\title{
Larvicidal Activitity of Some Medicinal Plant Crude Aqueous Extracts Against the Bancroftian Filariasis Vector, Culex Quinquefasciatus
} \section{Nadia Nour el Din Abdel Gadir ${ }^{*}$, Hatil Hashim EL-Kamali ${ }^{2}$, Hind Awad Abdalla ${ }^{3}$, Hagir Mahgoub Mohammed ${ }^{3}$, Asrar} Mohammed Ahmed ${ }^{3}$

${ }^{1}$ Department of Basic Science, Faculty of Nursing science, Omdurman Islamic University, Omdurman, Sudan

${ }^{2}$ Department of Botany, ${ }^{3}$ Department of Zoology, Faculty of Science and Technology, Omdurman Islamic University, Omdurman, Sudan

DOI: $10.36347 /$ sajb.2020.v08i11.003

| Received: 16.10 .2020 | Accepted: 31.10 .2020 | Published: 19.11 .2020

*Corresponding author: Nadia Nour el Din Abdel Gadir

Abstract Original Research Article

Aqueous extracts of dried Conyza aegyptiaca (Asteraceae) aerial parts, Morettia phillaeana (Del.) DC. (Brassicaceae) aerial parts, Acacia mellifera (Vahl.) Benth. (Mimosaceae) stem bark and Fagonia cretica L. (Zygophyllaceae) aerial parts were tested for larvicidal activity against the third instar larvae of the mosquito Culex quinquefasciatus Say. Extracts of $C$. aegyptiaca $\left(\mathrm{LC}_{50}=1.55 \mathrm{mg} / \mathrm{ml}\right)$, M.phillaeana $\left(\mathrm{LC}_{50}=5.50 \mathrm{mg} / \mathrm{ml}\right)$, A.mellifera $\left(\mathrm{LC}{ }_{50}=4.79 \mathrm{mg} / \mathrm{ml}\right)$ and F.cretica $\left(\mathrm{LC}_{50}=13.80 \mathrm{mg} / \mathrm{ml}\right)$ were all promising as larvicides.

Keywords: Culex quinquefasciatus, larvicide, medicinal plants, Sudan.

Copyright $\left({ }_{0} 2020\right.$ The Author(s): This is an open-access article distributed under the terms of the Creative Commons Attribution 4.0 International License (CC BY-NC 4.0) which permits unrestricted use, distribution, and reproduction in any medium for non-commercial use provided the original author and source are credited.

\section{INTRODUCTION}

The selective pressure of conventional insecticides is enhancing resistance of mosquito populations at an alarming rate [1], increasing the demand for new products that are environmentally safe, target-specific and degradable. Although several plants have been reported for mosquitocidal activity, only new botanicals have moved from the laboratory to field use, because they are poorly characterized, in most cases active components are not determined and most of the works are restricted to preliminary screening.

Recently, the discovery of insecticide activity of phototoxins present in Asteraceae species has stimulated the interest in this plant family as part of the search for new plant derived insecticides [2].

The interest in the study of medicinal plants as a source of biologically active compounds has increased worldwide. In Sudan, extracts from several plants, including Acacia nilotica, Azadirachta indica, Balanites aegyptiaca, Calotropis procera, Citrullus colocynthis, Euphorbia acalyphoides, Gardenia lutea, Solanum incanum and Solenostemma argel show a potential activity against the mosquito larvae C.quinquefasciatus [3-6].

The objective of the present study was to evaluate larvicidal activity of selected Sudanese medicinal plants against mosquito larvae of
C.quinquefasciatus, the vector of Brancroftian filariasis in Sudan.

\section{MATERIALS AND METHODS Plant material}

Conyza aegyptiaca (Asteraceae) aerial parts, Morettia phillaeana (Del.) DC. (Brassicaceae) aerial parts, Acacia mellifera (Vahl.) Benth. (Mimosaceae) stem bark and Fagonia cretica L. (Zygophyllaceae) aerial parts were collected from different localities in Omdurman South, Khartoum State, and Central Sudan and identified by one author (Prof. H.H. EL-Kamali). A voucher specimen has been deposited at Department of Botany, Faculty of Science and Technology, Omdurman Islamic University, Sudan. After collection, the samples were washed with tap water and shade-dried.

For preparation of extracts, $20 \mathrm{~g}$ of each plant sample were separately macerated in distilled water for $24 \mathrm{~h}$ at room temperature $\left(30^{\circ} \mathrm{C}\right)$. The extracts were subsequently filtered through cotton and the volume was adjusted to $1000 \mathrm{ml}$ with distilled water for a stock concentration of $20 \mathrm{mg} / \mathrm{ml}$. Serial dilutions $(20 \mathrm{mg} / \mathrm{ml}$ to $1.5 \mathrm{mg} / \mathrm{ml}$ ) were made from the stock solution. Tap water without extract was used as a control solution.

\section{Test organisms}

Larvae of the mosquito Culex quinquefasciatus Say were collected from breeding sites on the University Campus in AL-Fettaehab, South Omdurman. After 
Nadia Nour et al., Sch Acad J Biosci, Nov, 2020; 8(11): 356-359

pipetting all larvae into a Petri dish, those larvae with late three instar characteristics were separated from the collection by examining under a binocular microscope. After separation, 25 of the larvae were released into 500 $\mathrm{ml}$ beakers containing $250 \mathrm{ml}$ of the test or control solution [6].

\section{Bioassays and larval mortality}

Mortality counts of larvae were made after $24 \mathrm{~h}$ of treatment in the test solution. Larvae were considered dead if they settled and remained motionless at the bottom of the test beaker, did not respond to either light stimulation or mechanical stimulation (taps on the beaker with a pencil), and did not recover life functions if washed and transferred to a control water solution. The lethal concentrations: $\mathrm{LC}_{50}$ and $\mathrm{LC}_{90}$ values were calculated following the method of Finney, 1971.

Mortality was determined according to Abbot s, (1925) formula:

Treatment mortality \% - Control mortality \% 100 - Mortality \% control

\section{RESULTS AND DISCUSSION}

The lethality of Conyza aegyptiaca aerial parts, Morettia phillaeana (Del.) DC. aerial parts, Acacia mellifera (Vahl.) Benth. stem bark and Fagonia cretica L. aerial parts on mosquito larvae at different concentrations under laboratory conditions are presented in Tables 1-5 and Figures 1-2.

Table-1: The lethality of Conyza aegyptiaca extracts on mosquito larvae

\begin{tabular}{|c|c|c|c|}
\hline Concentration (mg/ml) & Mortality (\%) & Log concentration $(\mathbf{X})$ & Probit (Y) \\
\hline 20 & 100 & 1.30 & 7.33 \\
\hline 10 & 96 & 1.0 & 6.75 \\
\hline 7 & 93 & 0.85 & 6.48 \\
\hline 6 & 83 & 0.78 & 5.95 \\
\hline 5 & 73 & 0.70 & 5.61 \\
\hline 2.5 & 63 & 0.40 & 5.33 \\
\hline 1.5 & 60 & 0.18 & 5.25 \\
\hline
\end{tabular}

Table-2: The lethality of Morettia phillaeana extracts on mosquito larvae

\begin{tabular}{|c|c|c|c|}
\hline Concentration $\mathbf{( m g / m l )}$ & Mortality (\%) & Log concentration (X) & Probit (Y) \\
\hline 20 & 96 & 1.30 & 6.75 \\
\hline 10 & 70 & 1.0 & 5.52 \\
\hline 7 & 56 & 0.85 & 5.15 \\
\hline 6 & 43 & 0.78 & 4.82 \\
\hline 5 & 30 & 0.70 & 4.48 \\
\hline 2.5 & 26 & 0.40 & 4.36 \\
\hline 1.5 & 13 & 0.18 & 3.87 \\
\hline
\end{tabular}

Table-3: The lethality of Fagonia cretica extracts on mosquito larvae

\begin{tabular}{|c|c|c|c|}
\hline Concentration (mg/ml) & Mortality (\%) & Log concentration (X) & Probit (Y) \\
\hline 20 & 66 & 1.30 & 5.41 \\
\hline 10 & 36 & 1.0 & 4.64 \\
\hline 7 & 30 & 0.85 & 4.48 \\
\hline 6 & 26 & 0.78 & 4.36 \\
\hline 5 & 26 & 0.70 & 4.36 \\
\hline 2.5 & 13 & 0.40 & 3.87 \\
\hline 1.5 & 10 & 018 & 3.72 \\
\hline
\end{tabular}

Table-4: The lethality of Acacia mellifera extracts on mosquito larvae

\begin{tabular}{|c|c|c|c|}
\hline Concentration (mg/ml) & Mortality (\%) & Log concentration (X) & Probit (Y) \\
\hline 20 & 93 & 1.30 & 6.48 \\
\hline 10 & 70 & 1.0 & 5.52 \\
\hline 7 & 63 & 0.85 & 5.33 \\
\hline 6 & 56 & 0.78 & 5.15 \\
\hline 5 & 46 & 0.70 & 4.90 \\
\hline 2.5 & 30 & 0.40 & 4.48 \\
\hline 1.5 & 16 & 0.18 & 4.01 \\
\hline
\end{tabular}


Table-5: Lethal concentration of studied plants

\begin{tabular}{|c|c|c|}
\hline \multirow{2}{*}{ Plant } & \multicolumn{2}{|c|}{ Lethal concentration $\mathbf{( m g / m l}$ ) } \\
\cline { 2 - 3 } & $\mathbf{L C}_{\mathbf{5 0}}$ & $\mathbf{L C}_{\mathbf{9 0}}$ \\
\hline Conyza aegyptiaca & 1.55 & 6.76 \\
\hline Morettia phillaeana & 5.50 & 18.62 \\
\hline Acacia mellifera & 4.79 & 19.50 \\
\hline Fagonia cretica & 13.80 & 30.90 \\
\hline
\end{tabular}

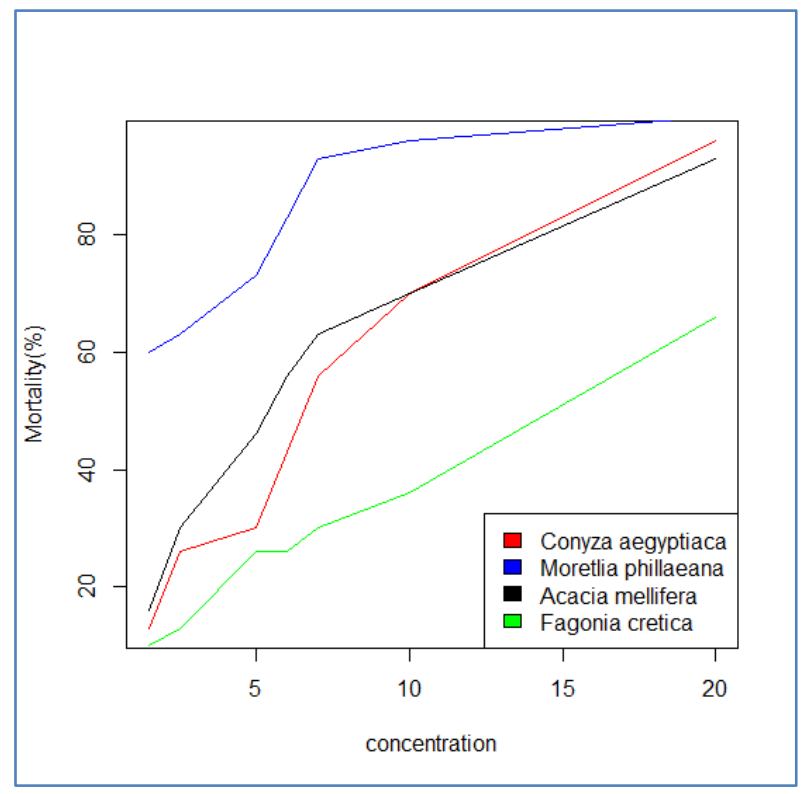

Fig-1: Dose response relationship for selected plant aqueous crude extract applied for 24 hours on Culex quinquefasciatus Say

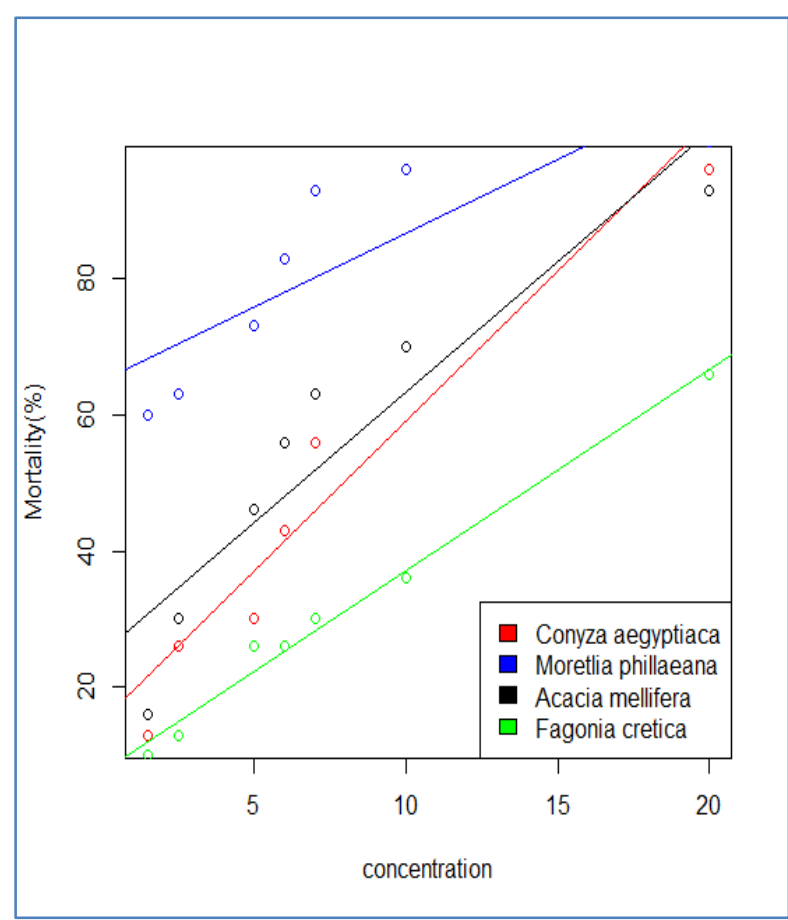

Fig-2: Probit mortality regression index of third instar of Culex quinquefasciatus after treatment with crude aqueous extracts
The toxicity data indicate that the crude aqueous extracts of these plants has high larvicidal activity. Based on the percentage of mortality demonstrated by the mosquito larvae, the lethality of the investigated plant species can broadly classified as highly toxic and moderately toxic. The first category (highly toxic: a dose of $<1.5 \mathrm{mg} / \mathrm{ml}$ to effect $50 \%$ larval mortality) on C.aegyptiaca. The second category (moderately toxic: a dose of $>6 \mathrm{mg} / \mathrm{ml}$ to effect $50 \%$ larval mortality) on M.phillaeana and a dose of $>10$ $\mathrm{mg} / \mathrm{ml}$ to effect $50 \%$ larval mortality on Fagonia cretica. The observed toxicities were also found to be concentration dependent.

Saponins are freely soluble in water and they work by interacting with the cuticle membrane of the larvae, ultimately disarranging the membrane, probable reason for larval death [7]. All investigated plants in this work were contains saponins $[8,6,9,10]$. Wiesman and Chapagin [1] reported that saponin extracted from Balanites aegyptiaca showed $100 \%$ mortality against larvae of Culex pipiens. The larvicidal property of saponin isolated from Cestrum diurnum was also evaluated against Anolpheles stephensi mosquito by Gosh and Chandra [12]. EL-Kamali [6] reported that crude aqueous extracts of dried fruit pericarp, flowers, root and stem of Solenostemma argel, Sudanese herb rich with saponins, were showed larvicidal activity agaist Culex quinquefasciatus. Isoflavonoids from tubers of Neoeautanenia mitis had a larvicidal effect against the malarial transmitting mosquitoes, Anopheles gambiae and Culex quinquefasciatus, respectively [13]. Studies with caraway, celery, fennel, mullilam and zedoary essential oils suggested that they are a biocontrol agent against mosquito vectors [14].

Our results relate to crude plant extracts and not to the purified active components, which, when isolated, would be expected to show much lower $\mathrm{LC}_{50}$ values than those reported here for the extracts. Identification of the active components for the larvicidal activity against Culex quinquefasciatus will be an important next step in the development of a verifiable application of these materials for the field control of the insect vector.

\section{CONCLUSION}

In conclusion, Conyza aegyptiaca offers promised as a potential biocontrol agent against Culex quinquefasciatus larvae. 


\section{REFERENCES}

1. Brown AW. Insecticide resistance in mosquitoes: a pragmatic review. Journal of the American Mosquito Control Association. 1986 Jun 1;2(2):123-40.

2. Rawls RL. Experts probe issues, chemistry of light-activated pesticides. Chemical \& Engineering News. 1986 Sep 22;64(38):21-4.

3. Zarroug IMA. Laboratory evaluation of plant extracts as larvicides. M.Sc. Thesis, University of Khartoum, Sudan. 1984.

4. Ali OE Larvicidal activity of some plant extracts against three species of mosquitoes. M.Sc. Thesis (Medical Entomology), University of Khartoum, Sudan; 1987.

5. Abdel Gadir IA. Larvicidal and Molluscicidal activities of some plant extracts against the larvae of Culex quinquefasciatus and the snails Biomphalaria Pfeifferi and Bulinus truncatus (Doctoral dissertation, M. Sc. Thesis, University of Khartoum).

6. El-Kamali HH. Larvicidal activity of crude aqueous extracts of Solenostemma argel against mosquito larvae. Journal of herbs, spices \& medicinal plants. 2001 Dec 6;8(4):83-6.

7. Hostettman K. Marston A. Saponins (chemistry and pharmacology of Natural Products). Cambridge University Press. 1995; 132.

8. Chhabra RS, Huff JE, Schwetz BS, Selkirk J. An overview of prechronic and chronic toxicity/carcinogenicity experimental study designs and criteria used by the National Toxicology
Program. Environmental health perspectives. 1990 Jun;86:313-21.

9. Khalik SA, Miyase T, El-Ashaal HA, Melek FR. Triterpenoid saponins from Fagonia cretica. Phytochemistry. 2000 Aug 1;54(8):853-9.

10. Ma L, Liu H, Qin P, Hu C, Man S, Li Y, Liu Z, Liu Z, Diao A. Saponin fraction isolated from Conyza blinii H. Lév. demonstrates strong anti-cancer activity that is due to its NF- $\kappa \mathrm{B}$ inhibition. Biochemical and biophysical research communications. 2017 Jan 29;483(1):779-85.

11. Chapagain B, Wiesman Z. Larvicidal effects of aqueous extracts of Balanites aegyptiaca (desert date) against the larvae of Culex pipiens mosquitoes. African Journal of Biotechnology. 2005;4(11).

12. Ghosh A, Chandra G. Biocontrol efficacy of Cestrum diurnum L.(Solanaceae: Solanales) against the larval forms of Anopheles stephensi. Natural product research. 2006 Apr 1;20(04):371-9.

13. Joseph CC, Ndoile MM, Malima RC, Nkunya MH. Larvicidal and mosquitocidal extracts, a coumarin, isoflavonoids and pterocarpans from Neorautanenia mitis. Transactions of the Royal Society of Tropical Medicine and hygiene. 2004 Aug 1;98(8):451-5.

14. Pitasawat B, Champakaew D, Choochote W, Jitpakdi A, Chaithong U, Kanjanapothi D, Rattanachanpichai E, Tippawangkosol P, Riyong D, Tuetun B, Chaiyasit D. Aromatic plant-derived essential oil: an alternative larvicide for mosquito control. Fitoterapia. 2007 Apr 1;78(3):205-10. 